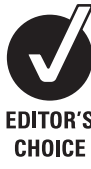

Correspondence to:

Dr T Swanwick, London

Deanery, Stewart House, 32

Russell Square, London WC1B

5DN, UK; tswanwick@

londondeanery.ac.uk

Received 10 February 2008

Accepted 5 May 2008

\title{
See one, do one, then what? Faculty development in postgraduate medical education
}

\author{
T Swanwick
}

\begin{abstract}
Interest in the development of medical educators working in the postgraduate sector is running high. Driven by three interlinked trends - the professionalisation of medical education, increasing accountability, and the pursuit of educational excellence - there is a growing need for high quality and sustained faculty development programmes across the network of education providers. Postgraduate medical education has a number of unique features that set it apart from undergraduate medicine, to which faculty development programmes need to cater. The key issue for the future will be how to engage the service in the business of education. Widespread cultural change is required and this will require effective and sympathetic leadership from postgraduate training institutions, hospitals and health authorities.
\end{abstract}

Mike works as a consultant in geriatric medicine in a large district general hospital. On Monday he arrives for the post-take ward round to meet his two Foundation doctors and specialist registrar, all eager (or at least looking eager) to learn. Following the ward round, during which he teaches on the management of a number of acute conditions, one of the Foundation doctors asks if he would observe her inserting a catheter for the purposes of her portfolio of workplace based assessment. Mike observes the procedure, gives the appropriate feedback and moves off to his clinic to be greeted by a pair of medical students sent to "sit in". After $3 \mathrm{~h}$ in outpatients, and a couple of student case presentations, he chats over lunch with a colleague who wants to talk through the management of a trainee with whom he is experiencing some difficulties. After lunch it's time for the departmental educational meeting where Mike leads an interprofessional discussion on the management of Parkinson's disease with his team. Later that afternoon, he meets his specialty registrar for an end of post review, and before going home he walks over to the postgraduate centre library to prepare for the lunchtime lecture that he is delivering tomorrow.

For most consultants, like Mike, medical education and training is an integral part of the working day. "Teaching" is something that is done in and around the primary task of patient care, usually without training or feedback on how it is being done. In the past it was assumed that anyone could teach, but is this really something that should be left to chance? Postgraduate medical education is changing. A move to professionalise medical education and a drive for excellence in education, coupled with an increasing accountability of clinical teachers, is raising the stakes. "Teaching the teachers", or faculty development, is no longer an added luxury, but a core activity with important consequences. In this article we will examine these drivers for change, and consider the uniqueness of postgraduate medical education and the competencies required of today's clinical teachers. Finally, several challenges for postgraduate medical education are identified, at the centre of which lie faculty development.

\section{WHAT IS FACULTY DEVELOPMENT AND WHY IS IT IMPORTANT?}

Steinert ${ }^{1}$ describes faculty development as:

\begin{abstract}
"...a planned program, or set of programs, designed to prepare institutions and faculty members for their various roles, with the goal of improving instructor's knowledge and skills in the areas of teaching, research and administration"
\end{abstract}

Faculty development is more that just about "teaching the teachers to teach". It should be an institution-wide pursuit with the intent of professionalising the educational activities of clinical teachers, enhancing educational infrastructure, and building educational capacity for the future-in other words, establishing education and training at the centre of what clinician trainers, and trainees, do. The "planned program" aspect of faculty development is particularly important, as not only should faculty development provide entry level training for novice clinical teachers, there must also be opportunities of ongoing professional development and support.

The perceived importance of faculty development in postgraduate medical education is founded on the belief that well trained doctors carry out better patient care. This in turn holds a number of key assumptions, namely that:

- there are some good-and less good-ways to facilitate learning

- training the trainers results in better trainee outcomes

- investing in human capital enhances organisational outputs.

Three forms of teaching have historically held sway in medical education: "the sage on the stage", "hanging around with the big boys" (also known as "learning by lurking"), and "teaching by humiliation". All have their problems. The traditional lecture format has been known for over 40 years to be a poor vehicle for the transfer of knowledge $e^{2}$ with only $42 \%$ of the key point of a lecture being recalled immediately afterwards, dropping to $20 \%$ within a week and to $3-5 \%$ thereafter. Despite these depressing figures, the lecture continues to be the staple diet of postgraduate education centres. 
Simply being around bigger and better doctors may well be an effective way to learn, but only if the trainee is provided with opportunities to contribute and participate. ${ }^{3}$ Without permission to join in with the activities of seniors, the trainee is confined to the role of passive spectator, and the learning experience is impoverished.

Finally, teaching by humiliation - the ritualistic dismantling of trainees on the ward round-though hopefully on the wane, has been shown to undermine the self confidence needed for the professional development of trainees and students. ${ }^{45}$

There are better ways to teach, underpinning most of which is the growing recognition that adult education benefits from a shift in emphasis from teaching to learning - that is, away from the activities of the teacher to the development of the learner. In this way the task of the clinical teacher changes from that of transmitting knowledge to structuring learning experiences. Space does not permit a detailed exploration of the educational literature, but a good summary of the theoretical bases to effective medical education can be found in the Association for the Study of Medical Education's excellent series of extended papers, Understanding medical education. ${ }^{6}$ Later in this article we will also examine some of the features that make postgraduate medical education unique.

\section{DOES FACULTY DEVELOPMENT MAKE A DIFFERENCE?}

There is, sadly, very little evidence that good teaching produces better trainees. What evidence there is comes mainly from the USA, in particular from some important studies by Griffith ${ }^{7}$ and Stern. ${ }^{9}$ Small positive effects on student's examination scores were found with better clinical teachers. A further key finding of Roop and Pangaro ${ }^{10}$ was that it was the resident, rather than the attending physician, who made the most difference to the cognitive growth of students. This has an important implication-faculty development is not just about developing the educational competencies of consultants, but the whole team.

Finally, faculty development is important because of its effect on the institution as a whole. Investing in human capital has been demonstrated to be beneficial to organisational output for over 200 years, ever since Robert Owen provided his workers at his highly productive New Lanark mills with food, shelter and free education and welfare. Numerous organisational and

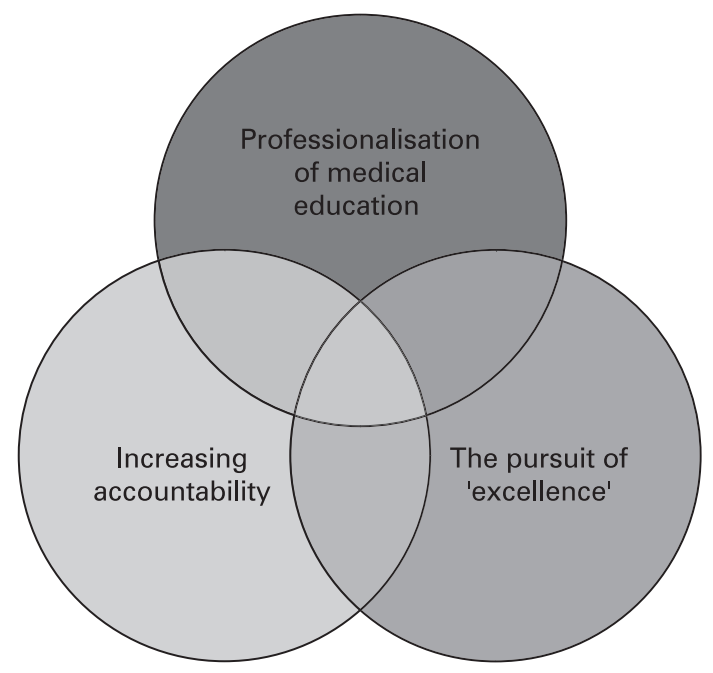

Figure 1 Drivers for faculty development in postgraduate medical education. motivational theorists have since propounded the importance of investing in people $e^{11-13}$ and where education is concerned, Senge has argued that learning organisations:
"... where people continually expand their capacity to create the results they truly desire, where new and expansive patterns of thinking are nurtured, where collective aspiration is set free, and where people are continually learning to see the whole together"13

are flexible, adaptive and productive.

\section{WHY NOW?}

Faculty development has assumed a heightened importance in recent years. From a UK perspective, this is as a result of three interlinked trends; the professionalisation of medical education, born out of an increasing sense of accountability, and the pursuit of excellence (fig 1).

\section{Professionalisation of medical education}

The move to place medical education on a more professional footing has been long in gestation. There has been concern at the standard of clinical teaching in medicine for a number of years, not only in the UK but elsewhere in the world. ${ }^{14}$ In the UK, driven in part by recommendations of the Dearing report on the future of higher education ${ }^{15}$ (box 1), there has been a growth in the number of departments of medical education attached to medical schools, and a proliferation of masters level programmes and postgraduate certificates, ${ }^{16}$ with huge international conferences and membership of organisations such as the Association for the Study of Medical Education at an all time high.

The most recent development is the formation of the Academy of Medical Educators which sets out to be:

"the professional organisation for all involved in the education and training of medical students and doctors... the Academy exists to provide leadership, promote standards and support all those involved in the academic discipline of medical education"17

Along the way there have been various attempts to define the expected competencies of clinical teachers and a number of "standards for medical educators" statements exist such as those produced in the UK by Harden ${ }^{18}$ and Hesketh et al, ${ }^{19}$ and further afield by the World Federation on Medical Education. ${ }^{20}$ The Academy of Medical Educators is expected to produce its own framework for professional development later in 2008.

\section{Increasing accountability}

The increased accountability of professionals working in the public sector is an inescapable fact of 21 st century life. In

\section{Box 1: National Committee of Inquiry into Higher} Education ${ }^{15}$

- Recommendation 13: We recommend that institutions of higher education begin immediately to develop or seek access to programmes for teacher training of their staff, if they do not have them, and that all institutions seek national accreditation of such programmes from the Institute for Learning and Teaching in Higher Education. 
medical education, this accountability is felt in a number of directions; to the patient, through government agendas around "patient choice" and "patient safety"; to the trainee as witnessed by the increasing importance laid on student evaluations, particularly in the USA, through to a growing number of appeals and legal challenges; and to regulatory bodies, a role taken in the UK by the Postgraduate Medical Education and Training Board (PMETB).

One of the manifestations of this increasing accountability is the recent articulation of training curricula for all specialties in the UK. For the first time, the competencies required by a trainee by the time of qualification are open to public scrutiny. Trainees can be expected to be tested against such curricula which, in turn, educators must now deliver. Great expectations indeed!

\section{Pursuit of "excellence"}

"Excellence" and "world classness" are the current political buzzwords in the UK public sector, cascading from the prime minister down. Wherever you look, "excellence in education" is a byword for reform. The recent review of UK postgraduate education and training, the Tooke report, was launched last year under the title "Aspiring to excellence"21 and PMETB are at it too:

"Our vision is to achieve excellence in postgraduate medical education, training, assessment and accreditation throughout the UK"22

Whatever the motivation, the message is clear: postgraduate medical education is - at least for a while-considered to be an important activity, vital to the health of the UK National Health Service, and to be carried out to the best of our ability and beyond.

\section{WHAT SORT OF FACULTY DEVELOPMENT?}

Faculty development programmes the world over have tended to focus on the improvement of individual teaching abilities across a broadly similar range of activities. ${ }^{1423}$ A typical content list is provided in box $2 .^{24}$

Faculty development has tended to be delivered as either ad hoc short courses or workshops or as accredited university

Box 2: Typical content of a postgraduate faculty development programme ${ }^{24}$

- Feedback

- Teaching skills

- Supervision

- Workplace based assessment

- Objective setting

- Learning needs analysis

- Appraisal

- Careers advice

- Working with portfolios

- Management of poor performance

- Diversity and equal opportunities

- Educational theory

- Small group facilitation

- Lecturing

- Team development

- Management and leadership of educational change awards, such as postgraduate certificates, diplomas or masters degrees. More innovative approaches have also included: longitudinal programmes, where faculty commit a proportion of their time on a regular basis over 1-2 years to develop their knowledge and skills ${ }^{25}$; individual coaching, such as the Kent, Surrey and Sussex Deanery's Certificate in Teaching ${ }^{26}$; mentorship $^{27}$; and e-learning. ${ }^{24}$

A recent systematic review looking at effectiveness of faculty development programmes ${ }^{28}$ found that the key features contributing to their effectiveness were:

- use of experiential learning

- provision of feedback

- effective peer/colleague relationships

- well designed interventions following established educational principles

- use of a diversity of educational methods within single interventions.

Overall satisfaction with the programmes described in the papers analysed was high, with participants reporting improvements in their teaching behaviours which were also picked up by students. Although changes in organisational practice were not often recorded, reported changes included greater educational involvement and the development of collegial networks. This would support the wider benefits of faculty development to an institution described above.

\section{KEY FEATURES OF POSTGRADUATE MEDICAL EDUCATION}

Much of the faculty development literature derives from the undergraduate sector, where with some exceptions (notably problem based learning) the emphasis has been on transmission rather than the acquisition of knowledge and skills, with the prime purpose of the surrounding institution being student learning.

Postgraduate medical education takes place in a very different environment. Teaching and learning is carried out in situ, by clinicians who see their primary responsibility as the delivery of patient care. This has led to a number of characterising features that, though not unique, predominate in this sector.

\section{Work based learning}

Work based learning, defined as learning for work, learning at work and learning from work, ${ }^{29}$ is fundamental in postgraduate medical education where experiential "learning on the job" has been a modus operandi for centuries. A number of areas of work based learning have roused interest in recent years. The first of these is what Eraut ${ }^{30}{ }^{31}$ terms non-formal learning-the learning that takes place during or between professional tasks, sometimes even without the participant having been aware of what was learned. Second is the apprentice model of education in which initiates spend time on the job in the hope that they will acquire the knowledge, skills and professional attitudes necessary to become a master. Lave and Wenger ${ }^{32}$ famously characterised this socio-cultural progression from newcomer to old-timer as "legitimate peripheral participation in a community of practice", a process by which the novice learns to talkthe-talk and walk-the-walk. Finally, there is an increasing focus on interprofessional learning in which "two or more professions learn with, from and about each other to improve collaboration and the quality of care". ${ }^{33}$

\section{Supervision}

A great deal of postgraduate education takes place as a result of professional conversations between colleagues. Much of this 
occurs as a one-to-one. Examples of such developmental conversations would include tutorials, mentoring, remedial supervision, and appraisal. The terminology in this area is overlapping and frequently confused, though Launer has helpfully brought much of the literature together under the blanket term "supervision" - a concept that may focus on development or performance or both, dependent on the context of the conversation. ${ }^{34}$ In postgraduate medical education in the UK we have also seen the widespread adoption of the terms "clinical" and "educational supervision", ${ }^{35}$ terms that distinguish between the day-to-day looking over the shoulder of the trainee (clinical supervision) and concern with their overall educational trajectory (educational supervision).

\section{Performance assessment in clinical settings}

Workplace based assessments are now in widespread use across all specialty training curricula in the UK, having begun life in the Foundation Programme in 2005. Traditionally, medical assessment focused on ritualistic end point summative assessments conducted far away from the place of work. Increasingly, assessments of medical competence now examine the actual performance of trainee doctors in their work setting. Qualitative approaches to the collection of assessment evidence are being adopted as the "one-trait one-test" approach is being replaced by the building of a triangulated rich picture over time, reflecting not just what doctors do (or say they will do) in a controlled examination situation, but what they actually do at work with real patients. ${ }^{36} 37$

\section{Patient safety}

Learning "on the job" will inevitably put patients in the way of some risk or inconvenience. One of the tasks of the postgraduate clinical teacher is to minimise this risk while maximising the educational opportunity. This not only requires eyes in the back of the head but a well developed sensitivity to the needs of the patient, the trainee and the service. Knowing when to take over and when to let go are key skills here.

\section{Delivering education, training and service}

Unlike teachers in schools, or lecturers in universities, the postgraduate medical faculty have a day job. Apart from the clinical load, there are departments and hospitals to run, correspondence to deal with and often a private practice to manage. Trainees too have to man out-of-hours rotas and deliver a service at the same time as satisfying the curriculum and assessment requirements and conforming to working time restrictions. It is easy for education to be drowned out by such clinical and administrative burdens.

\section{CHALLENGES FOR FACULTY DEVELOPMENT IN POSTGRADUATE MEDICAL EDUCATION}

In the UK, faculty development is patchy, concentrated around teaching hospitals and sporadically funded through postgraduate training institutions (deaneries). The main barriers to training the trainers are cited as funding constraints and the lack of time formally recognised in job plans. Targeting clinical teachers themselves as a sole strategy for implementation is unlikely to achieve the goals of faculty development, a fact that is recognised in the Tooke report ${ }^{21}$ :

"Training implications need to be reflected in appropriate staff development as well as job plans and related resources" (Recommendation 29)
And this is not just a UK problem. Evidence suggests that local delivery of faculty development in the USA is also problematic. $^{23}$ In a study of 108 teaching hospitals, only $39 \%$ had ongoing faculty development programmes, with university affiliated hospitals much more likely to provide ongoing faculty development than non-university hospitals. Only 14\% of sites offered "advanced programmes", as defined by programmes lasting more than 2 days, offering 10 or more topics, and using three or more experiential teaching methods. Factors identified to facilitate participation in faculty development activities included supervisor attitudes, on site expertise, and institutional culture.

Outside hospital, in the UK at least, the picture is more rosy. For some time, general practice has given due recognition to its trainers, who receive a one session/week training payment, as well as $100 \%$ reimbursement of the trainee's salary. It is perhaps not surprising then that the requirements to become a trainer in general practice are the most exacting of all specialties, with many areas of the country requiring the possession of a university accredited postgraduate certificate in education before applicants can apply to take on the role.

Wherever we look, there is a clear overlap between the needs of the undergraduate and postgraduate faculties, two sectors that could clearly work better together in delivering an enhanced service to their students and trainees.

\section{WHERE NEXT WITH FACULTY DEVELOPMENT?}

A quality agenda for postgraduate medical education is emerging, with heightened requirements for clinical teachers already in view. PMETB has published its expectations of training in a set of generic quality domain ${ }^{38}$ and the Gold Guide to Specialty Training ${ }^{39}$ has laid out the training requirements for clinical and educational supervisors. Trainee feedback is also there in the form of the national trainee survey. The thumbscrew of standards for medical educators is likely to tighten further and, as a result, medical educators are then likely to seek accreditation either through university courses, or through professional routes provided, for example, by the Academy of Medical Educators.

This development will not be confined to consultants, and trainees will want to undertake training courses before qualifying as requirements for "teacher training" feature in both Foundation and specialty training curricula.

There are service changes afoot as well which will affect the way that postgraduate education is delivered. Working time directives limiting the length of the working week and the establishment of shift systems will mean the final collapse of the "firm" structure, with the need for more formal training

\section{Key messages}

- The professionalisation of medical education, increasing accountability and the pursuit of educational excellence have made faculty development a pressing need for providers of postgraduate medical education.

- Postgraduate medical education has a number of unique features which set it apart form undergraduate medical education.

- The implementation of wholesale faculty development programmes will require effective and sympathetic leadership from postgraduate training institutions, hospitals and health authorities. 
arrangements to be put in place and a shift of patient care from hospital to the community which will require clinical teachers of secondary care specialties in a primary care environment.

The key issues will be to engage the service in the business of education, which will be largely dependent on how the funding of training posts is orchestrated in the future, and to negotiate meaningful job plans that value education as a core, rather than as a peripheral activity.

Although the two could work much closer together than they currently do, postgraduate medical education has some unique features and competencies that set it apart from its undergraduate cousin. If the sector is to meet the challenges laid down by its professional bodies, regulators and patients, widespread cultural change is required. This will require effective and sympathetic leadership from postgraduate training institutions, hospitals and health authorities.

Competing interests: The author is the Faculty Development Lead for the London Deanery, a member of Council for both the Association for the Study of Medical Education and the Academy of Medical Educators, and Editor of the series Understanding Medical Education.

\section{REFERENCES}

1. Steinert Y, Mann K. Faculty development: principles and practices. J Vet Med Educ 2006;33:317-24.

2. Verner C, Dickinson G. The lecture: An analysis and review of research. Adult Education 1967:17:85-100.

3. Swanwick T. Informal learning in postgraduate medical education: from cognitivism to 'culturism'. Med Educ 2005;39:859-65.

4. Cheetham G, Chivers G. How professionals learn in practice: an investigation of informal learning amongst people working in professions. J Eur Industrial Training 2001;25:248-92.

5. Metcalfe DH, Matharu M. Student's perceptions of good and bad teaching: report of a critical incident study. Med Educ 1995;29:193-7.

6. Kaufman D, Mann K. Teaching and learning in medical education: how theory can inform practice. In: Understanding medical education. Edinburgh: Association for the Study of Medical Education, 2007.

7. Griffith CWJ, Haist SA, Ramsbottom-Lucier M. Relationships of how well attending physicians teach top their student's performances and residency choices. Acad Med 1997;72:S118-20.

8. Griffith CWJ, Haist SA, Ramsbottom-Lucier M. Do students who work with better housestaff in their medicine clerkships learn more? Acad Med 1998;73(supp):S57-9.

9. Stern DT, Williams BC, Gill A, et al. Is there a relationship between attending physicians' and residents' teaching skills and students' examination scores? Acad Med 2000;75:114-16.

10. Roop SA, Pangaro L. Effect of clinical teaching on student performance during a medicine clerkship. Am J Med 2000;110:205-9.

11. Argyris C. Integrating the individual and the organization. New York: Wiley, 1964.

12. Carnall C. Managing change in organizations. London: Prentice-Hall, 1995.

13. Senge P. The fifth discipline: the art and practice of the learning organization. New York: Doubleday, 1990.
14. Wall D, McAleer S. Teaching the consultant teachers: identifying the core content. Med Educ 2000;34:131-8.

15. Dearing R. Higher education in the learning society: National Committee of Inquiry into Higher Education. London: HMSO, 1997.

16. Pugsley L, Brigley S, Allery L, et al. Making a difference: researching masters and doctoral research programmes in medical education. Med Educ 2008;42:157-63.

17. Academy of Medical Educators. www.medicaleducators.org/ (Accessed 4 February 2008).

18. Harden RM, Crosby JR, Davis MH. AMEE Guide No.14 Outcome-based education: part 1. An introduction to outcome-based education. Med Teach 1999;21:7-14.

19. Hesketh EA, Bagnall G, Buckley EG, et al. A framework for developing excellence as a clinical educator. Med Educ 2001;35:555-64.

20. World Federation on Medical Education Task Force. Defining international standards in basic medical education. Med Educ 2000;34:665-75.

21. Tooke J. Aspiring to excellence: final report of the independent inquiry into modernising medical careers. London: Aldridge Press, 2008.

22. Postgraduate Medical Education and Training Board, 2008. www.pmetb.org uk. (Accessed 4 February 2008).

23. Clark JM, Houston TK, KolodnerK, et al. Teaching the teachers: national survey of faculty development in departments of medicine of US teaching hospitals. J Gen Intern Med 2004;19:205-14.

24. London Deanery. Faculty development: a curriculum for clinical teachers. London: London Deanery, 2008.

25. Steinert Y, Nasmith L, McLeod PJ, et al. A teaching scholars programme to develop leaders in medical education. Acad Med 2003;78:142-9.

26. Kent Surrey and Sussex Deanery. Certificate in Teaching. 2008.

27. Connor M, Bynoe AG, Redfern N, et al. Developing senior doctors as mentors. Med Educ 2000;34:747-53.

28. Steinert Y, Mann K, Centeno A, et al. A systematic review of faculty development initiatives designed to improve teaching effectiveness in medical education. Med Teach 2006;28:497-526

29. Seagraves L, Osborne M, Neal P, et al. Learning in smaller companies, final report. Stirling: University of Stirling, 1996

30. Eraut M. Non-formal learning and tacit knowledge in professional work. Br J Educ Psychol 2000;70:113-36.

31. Eraut M. Informal learning in the workplace. Studies in Continuing Education 2004;26:247-73.

32. Lave J, Wenger E. Situated learning: legitimate peripheral participation. Cambridge: Cambridge University Press, 1991.

33. Centre for the Advancement of Interprofessional Education. Interprofessional education - a definition. CAIPE Bulletin 1997:13:9.

34. Launer J. Clinical supervision, mentoring and coaching. In: Swanwick T, ed. Understanding medical education. Edinburgh: Association for the Study of Medical Education, 2006.

35. Kilminster S, Cottrell D, Grant J, et al. AMEE Guide No. 27: Effective educational and clinical supervision. Med Teach 2007;29:2-19.

36. Swanwick T, Chana N. Workplace assessment for licensing in general practice. Br J Gen Pract 2005;55:461-7.

37. Postgraduate Medical Education and Training Board Workplace Based Assessment Subcommittee. Workplace based assessment. Postgraduate Medical Education and Training Board, 2005.

38. Postgraduate Medical Education and Training Board. Generic standards for training. 2006. http://www.pmetb.org.uk/fileadmin/user/Policy/Policy Statements/ Generic standards for training April 06.pdf (Accessed 4 February 2008).

39. Department of Health. A guide to postgraduate medical education in the UK (The Gold Guide). MMC: Department of Health, 2007. 